\title{
Regiões Euler: um Estudo sobre Distância Tonal e Integração entre os Ciclos Octatônicos e Hexatônicos
}

\author{
Euler Regions: a Study on Tonal Distance and \\ Integration between Octatonic and Hexatonic Cycles
}

\author{
Paulo de Tarso Salles \\ Universidade de São Paulo - USP \\ ptsalles@usp.br
}

Resumo: Este trabalho apresenta um estudo sobre distância tonal a partir de certos pressupostos estabelecidos por David Lewin (1982), Richard Cohn (1996; 2012), Jack Douthett \& Peter Steinbach (1998), Clifton Callender (1998), Steven Baker (2003) e Dmitri Tymoczko (2011), entre outros. Demonstra como os ciclos octatônicos (descritos por Douthett e Steinbach), formados por acordes de sétima, podem conectar-se com as tríades consonantes dos ciclos hexatônicos (descritos por Cohn). Tal conexão entre acordes de diferentes cardinalidades é possível por meio de uma região harmônica denominada "região Euler", em referência a um trabalho publicado pelo matemático e teórico Leonhard Euler no século XVIII, no qual uma topologia de tríades aumentadas resulta em acordes maiores com sétima maior. Uma breve análise de um quarteto de Villa-Lobos ilustra a importância das regiões Euler entre as tétrades e tríades perfeitas.

Palavras-chave: teoria neo-riemanniana; distância tonal; Villa-Lobos; análise musical.

Abstract: This paper brings a study on tonal distance grounded on some concepts established by David Lewin (1982), Richard Cohn (1996; 2012), Jack Douthett \& Peter Steinbach (1998), Clifton Callender (1998), Steven Baker (2003), and Dmitri Tymoczko (2011), among other distinguished theorists. It demonstrates how the octatonic cycles (as described by Douthett \& Steinbach) can connect to the hexatonic cycles (as described by Cohn), linking chords with different cardinalities (seventh chords connected to consonant triads). "Euler region" is a tonal space proposed to provide such connection between those cycles, a region 
named after Leonhard Euler, an 18th century theorist and mathematician who published a topology with augmented triads that results in major chords with major seventh. A brief analysis of a Villa-Lobos's string quartet illustrates the role of Euler regions between seventh chords and consonant triads.

Keywords: neo-Riemannian theory; tonal distance; Villa-Lobos; music analysis.

\section{1 - Introdução}

Este trabalho complementa o conteúdo apresentado em conferência no último SIMPOM, Simpósio de Pós-Graduandos em Música, organizado pela Unirio. $^{1}$ Naquela ocasião foi apresentado um histórico de algumas representações do espaço tonal que vem sendo reinterpretadas e reelaboradas por teóricos da vertente neo-riemanniana. A narrativa remonta à tonnetz de Leonhard Euler (1774), passando pelos modelos de Arthur von Oettingen (1866), Hugo Riemann (1915) até a releitura empreendida por David Lewin (1982) e Brian Hyer (1989). Após a adoção do sistema temperado, a tonnetz tornou-se uma ferramenta analítica capaz de demonstrar processos dinâmicos ocorrendo em um espaço tonal e triádico, representada geometricamente como um espaço finito. ${ }^{2}$ Explorações posteriores, feitas por Richard Cohn (1996) e Jack Douthett \& Peter Steinbach (1998) apresentam modelos de sistematização de tríades e tétrades segundo a noção de "caminho mais curto" ou "parcimônia", onde os acordes são dispostos de acordo com a menor movimentação possível, o deslocamento de semitom. ${ }^{3}$

Richard Cohn denominou de "ciclos hexatônicos" o conjunto de 24 tríades consonantes dispostas parcimoniosamente; seu trabalho prossegue com o resgate da teoria desenvolvida por Carl Friedrich Weitzmann (1853) sobre a tríade aumentada e suas transformações semitonais, que Cohn batizou "regiões Weitzmann". Cada tríade aumentada apresenta seis dessas transformações

\footnotetext{
${ }^{1}$ Salles, 2016.

${ }^{2}$ A matriz de Oettingen e a tabela de Riemann baseiam-se na afinação justa, a qual resulta em oitavas imperfeitas e num campo harmônico potencialmente infinito. Lewin e Hyer, ao retomarem o conceito de tonnetz de Riemann, adotam o sistema temperado e o conceito de classes de alturas dele decorrente.

${ }^{3}$ Há pelo menos três conceitos diferentes de "parcimônia": o de Richard Cohn (1996), para quem apenas os movimentos de semitom são parcimoniosos; o de Douthett \& Steinbach (1998), que inclui o deslocamento por dois semitons; e o de Adrian Childs (1998), específico para tétrades, com movimento de duas vozes. Steven Baker (2003) propõe "classes de deslocamento" para tratar das transformações contextuais entre acordes de sétima. Neste trabalho será adotada, na maior parte dos casos, a noção proposta por Cohn, embora ocasionalmente o método de Douthett \& Steinbach possa ser usado. Em um estudo preliminar, chamei esse tipo de movimentos de condução de vozes como "deslizamento de semitons" (Salles, 2009:132-9).
} 
decorrentes do movimento por semitom, três delas resultando em tríades maiores, outras três em tríades menores; Cohn observa que essas transformações conectam os ciclos hexatônicos e, a partir disso, Douthett e Steinbach desenvolveram um gráfico chamado de "dança dos cubos" (cube dancing) onde os quatro ciclos hexatônicos estão interligados pelas quatro tríades aumentadas, também de acordo com a noção de caminho mais curto (Fig. 1). ${ }^{4}$

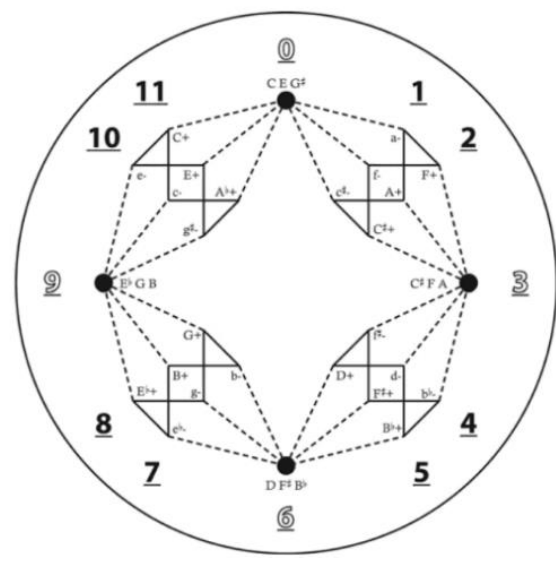

Figura 1: Gráfico "dança dos cubos", proposto por Douthett e Steinbach (1998) a partir dos hexaciclos de Cohn (extraído de Cohn, 2012, p. 104)

O trabalho de Douthett e Steinbach (1998) avançou no sentido de empreender sistematização semelhante em relação aos acordes de sétima. Quando esses acordes são dispostos parcimoniosamente resultam em três ciclos, batizados como "torres octatônicas" (Octa Towers), já que as classes de altura de cada ciclo formam uma coleção octatônica (Fig. 2). Os acordes menores com sétima estão a meio caminho entre os acordes meio-diminutos e os de sétima de dominante, no centro das "torres". É possível conectar as três torres octatônicas com os três acordes de sétima diminuta (as "regiões Boretz"), cujo resultado é o gráfico denominado "torres de força" (Power Towers) (Fig. 3).

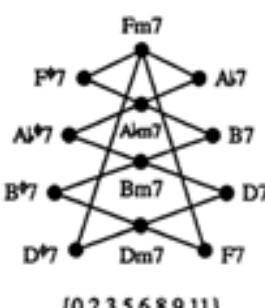

$[0,2,3,5,6,8,9,11]$

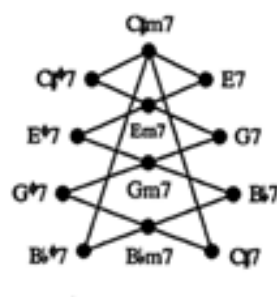

$(1,2,4,5,7,8,10,11)$

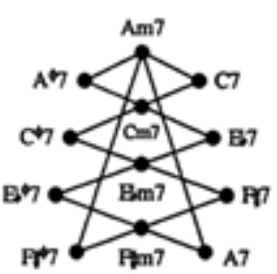

$\{0,1,3,4,6,7,9,10\}$

Figura 2: Torres octatônicas, elaboradas por Douthett e Steinbach (1998, p. 246)

\footnotetext{
${ }^{4}$ Na representação feita por Douthett \& Steinbach, os "cubos" são distorcidos nos vértices que contém as tríades aumentadas, ficando alongados nessas extremidades.
} 


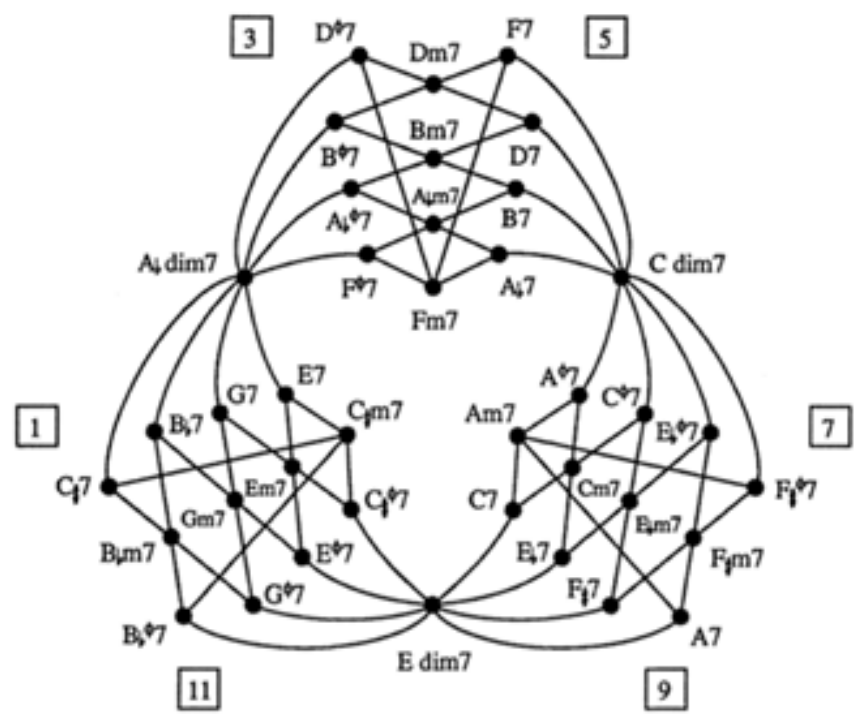

Figura 3: Gráfico das “torres de força” de Douthett e Steinbach (1998, p. 256)

Posteriormente, a dissertação de mestrado de Steven Baker (2003) retoma o gráfico das torres de força com a ideia de estabelecer conexões entre torres octatônicas e tríades. Baker observa que acordes maiores com sétima maior são caminhos alternativos aos acordes diminutos na interligação entre as torres octatônicas (Fig. 4); além disso, explorando a transformação SPLIT, proposta por Clifton Callender (1998), ele mostra como um acorde com sétima maior pode converter-se em uma tríade perfeita. Assim, no lugar de (ou paralelamente a) um acorde de sétima diminuta, Baker propõe quatro acordes de sétima maior ligando os acordes meio-diminutos de um ciclo aos acordes de sétima de dominante de outro ciclo. No gráfico proposto por Baker, as tríades são posicionadas assimetricamente: de um lado estão em um eixo situado "dentro" da torre octatônica, entre os acordes menores com sétima e meio-diminuto; e do outro lado estão inseridas fora da torre octatônica, antes dos acordes de sétima de dominante. Esse posicionamento assimétrico quebra a organização entre zonas de condução de vozes, já que a soma das classes de alturas nas tríades não corresponde com a soma verificada nas tétrades, resultando em considerável perda de consistência do gráfico. 


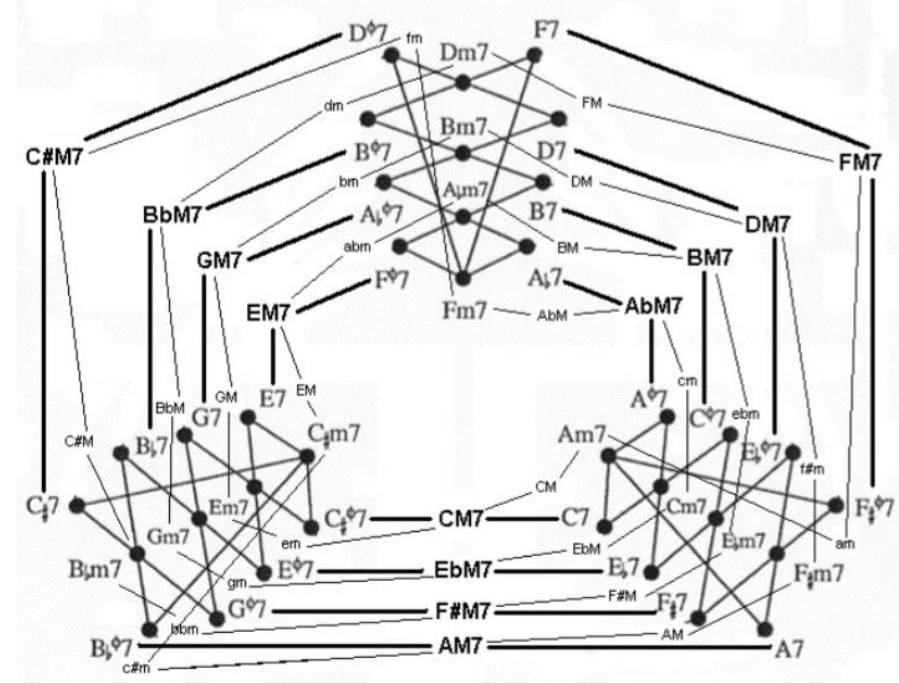

Figura 4: Gráfico de Steven Baker (2003, p. 64), ampliando as torres de força de Douthett e Steinbach

A proposta de Baker é interessante por mostrar a possibilidade de transitar entre acordes de cardinalidade diferente, e é a partir dela que proponho uma região intermediária entre os acordes de sétima maior e as tríades. No entanto, algumas análises de obras do início do século XX sugerem que há um hiato importante nesse gráfico. Vislumbra-se toda uma região não mapeada, onde acordes como os menores com sétima menor, maiores com sexta menor e a tétrade maior/menor intermediam a conexão entre tétrades e tríades. Uma reinterpretação da tonnetz de Euler indica como essa região pode ser delineada e compreendida nesse espaço tonal.

\section{2 - Regiões Euler}

Na tonnetz proposta por Euler (Fig. 5), a sequência vertical de tríades aumentadas resulta em uma progressão de acordes com sétima maior, resultantes das alturas situadas nos quatro vértices de cada quadrilátero, estabelecendo uma progressão de fundamentais (F7+, C7+, G7+, no quadrante superior; $\mathrm{A} 7+, \mathrm{E} 7+\mathrm{e} \mathrm{B} 7+$ na região inferior $)^{5}$ similar à que vemos em cada anel do diagrama de Baker (Fig. 4).

${ }^{5}$ A cifra "7+" indica acorde com sétima maior. 


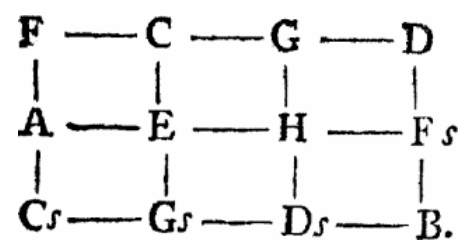

Figura 5: Tonnetz de Euler (1774), extraído de Gollin (2009, p. 406)

Os acordes com sétima maior, interpretados desta forma, passam a ser porta de entrada para um espaço tonal que denomino como "regiões Euler" (Fig. 6). Cada região Euler apresenta quatro ciclos, cada qual com três acordes, cujas fundamentais correspondem à progressão de terças maiores da tonnetz de Euler.

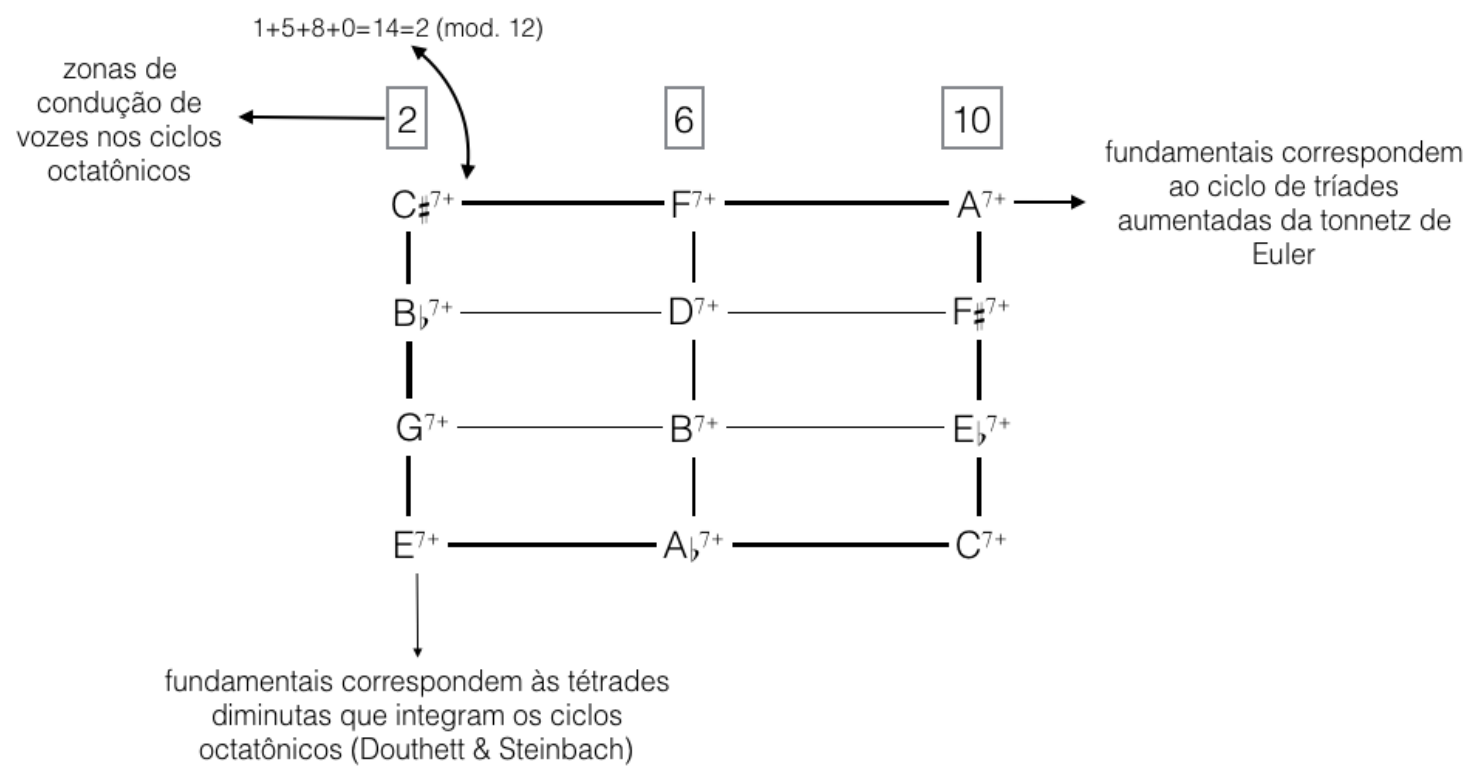

Figura 6: acordes da classe 4-20, porta de entrada para as regiões Euler.

Cada acorde de sétima maior pode conectar-se com acordes menores com sétima menor ou com acordes maiores com sexta menor acrescentada por movimento de semitom (Fig. 7). Esses acordes circundantes pertencem ao mesmo conjunto de classes de altura (CCA), cuja numeração Forte é 4-19; suas conformações se mapeiam por inversão, ${ }^{6}$ como é facilmente observável na representação circular (Fig. 8). O CCA 4-19 tem como elemento de base a tríade aumentada (indicada pela linha tracejada), à qual é acrescentado um intervalo de semitom; se o semitom acrescentado for superior às classes de altura da tríade

\footnotetext{
${ }^{6} \mathrm{O}$ critério adotado aqui para nomear as tétrades segue a noção "dualista" na qual, sob inversão, a tríade maior se mapeia em tríade menor e vice-versa.
} 
aumentada, isso resulta em um acorde menor com sétima menor (4-19A); ${ }^{7}$ se o semitom for inferior, resultará em uma tríade maior com sexta menor acrescentada (4-19B).

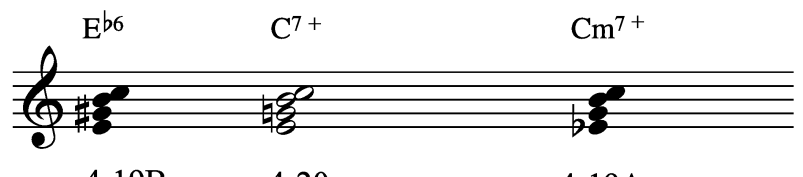
4-19B
4-20
4-19A

Figura 7: transformações semitonais entre as classes 4-19 e 4-20.

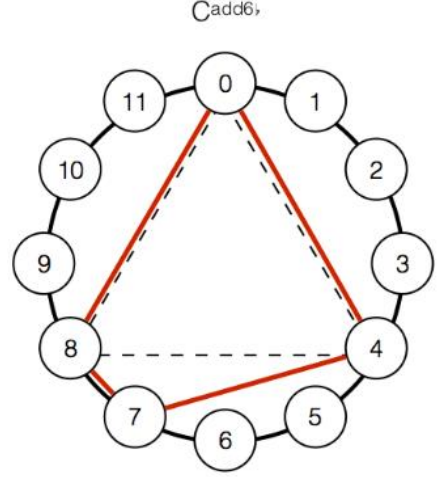

$[4,7,8,0]$

semitom inferior, 4-19B

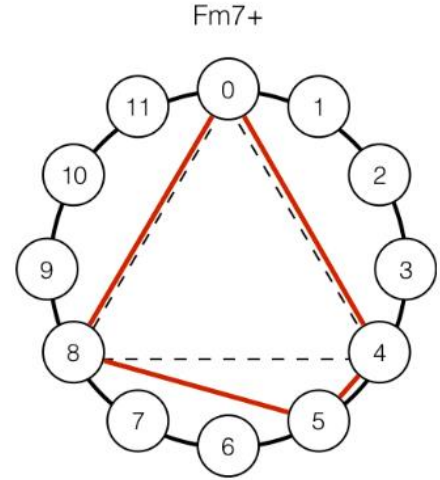

$[4,5,8,0]$

semitom superior, 4-19A

Figura 8: representação circular de acordes da classe 4-19.

Além dos CCA 4-19 e 4-20, a região Euler também apresenta o CCA 4-17, conhecido como tetracorde maior-menor. ${ }^{8}$ Acordes pertencentes ao conjunto 417 fecham o ciclo de transformações mínimas de uma região Euler, oferecendose como potencial conexão com os ciclos hexatônicos triádicos (Fig. 9).

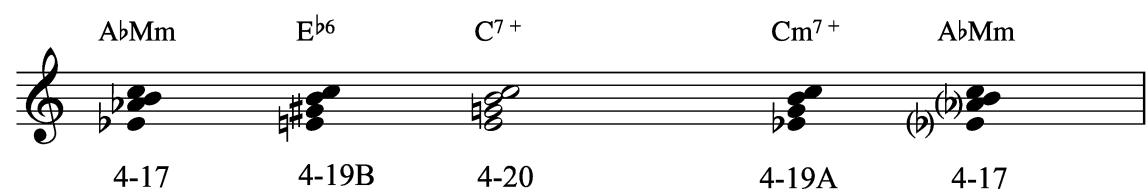

Figura 9: região Euler e suas transformações por semitom.

Com o acréscimo do tetracorde maior-menor, a região Euler fica completa, gerando quatro ciclos, numerados de fora para dentro (Tabela 1). Os acordes da

\footnotetext{
${ }^{7}$ Flo Menezes avalia a importância desse acorde na obra de Bach, Mahler e Berio (Menezes, 2016, p. 71-82).

${ }^{8} \mathrm{O}$ tetracorde maior-menor (FN 4-17) será cifrado como "Mm" nas ilustrações musicais.
} 
classe 4-17 podem sofrer uma retração por semitom - operação que Clifton Callender (1998) chamou função "SPLIT"9 - transformando-se em tríade, maior ou menor (CCA 3-11), assim as regiões octatônicas das "torres de força" podem ser conectadas com as zonas de condução de vozes dos ciclos hexatônicos (da "dança dos cubos"). No entanto, a tabela ainda não apresenta as conexões existentes entre o CCA 4-19 e as tríades aumentadas das regiões Weitzmann, que serão demonstradas mais adiante.

As regiões Euler podem ser visualizadas como ciclos de transformações por semitom, dispostos espacialmente de modo a serem inseridos entre as "torres de força" de Douthett e Steinbach (Fig. 10). Embora ligadas diretamente aos ciclos octatônicos, as regiões Euler também são fundadas na coleção hexatônica (6-20), o que provavelmente contribui para uma transição mais suave entre os ciclos octatônicos e os ciclos hexatônicos triádicos. Cada região Euler, portanto, é um ciclo hexatônico tetrádico (Fig. 11).

Uma versão posterior do gráfico "torres de força", atribuída por Richard Cohn a Jack Douthett, 10 incorpora o acorde de sexta francesa como caminho alternativo aos acordes menores com sétima na passagem entre os meiodiminutos e dominantes com sétima (Fig. 12). Pertencente à classe 4-25, o acorde de sexta francesa mapeia-se em si mesmo por transposição de seis semitons (trítono), o que equivale dizer que há apenas seis versões distintas desse acorde, ou seja, o acorde de sexta francesa com fundamental em Fá (F Fr) pode se mapear no mesmo tipo de acorde com fundamental em Si (B Fr), a fundamental Ré (D Fr) em Láb (Ab Fr), e assim por diante. Dmitri Tymoczko (2011, p. 106) demonstra como uma torre octatônica forma um conjunto de cubos em quatro dimensões, $\mathrm{o}$ tesserato (tesseract) (Fig. 13).

\section{3 - Interligando os Ciclos OCTA e HEXA}

Diante dessas possibilidades de representação, proponho um gráfico que integre os elementos apresentados acima: as "torres de força", os acordes de sexta

\footnotetext{
${ }^{9}$ Callender (1998, p.224-231) mostra como duas vozes podem se fundir em uma ou o oposto, quando uma voz pode se dividir (to split, em inglês) em duas, por movimentos de semitom. Em ambos os casos ocorre mudança de cardinalidade na transformação entre dois acordes. A função é nomeada genericamente como SPLIT, independente de ocorrer fusão ou divisão. O processo é ilustrado na Fig.15, sendo ligeiramente modificado por considerar a função SPLIT em movimento oblíquo, onde uma voz resultante permanece estacionária.

${ }^{10}$ Richard Cohn conta que Jack Douthett desenvolveu o gráfico "torres de força" em 1993, e quando Douthett e Steinbach publicaram esse material em 1998 as sextas francesas estavam ausentes; Tymoczko (2011, p.414) apresenta uma versão independente onde usa as sextas francesas em contexto semelhante (Cohn, 2012, p.157-158, n. 15).
} 
francesa e as regiões Euler em conexão com a "dança dos cubos", como um espaço transformacional de amplas possibilidades, as quais incluem mudança de cardinalidade.

\begin{tabular}{|c|c|c|c|c|c|c|}
\hline OCTA & 4-19B & $4-20$ & $4-19 \mathrm{~A}$ & $4-17$ & $3-11$ & Hexa Zona \\
\hline \multicolumn{7}{|c|}{ Regiões Euler } \\
\hline \multirow{6}{*}{ Ciclo 1} & \multirow{2}{*}{ F6b } & \multirow{2}{*}{$\mathrm{C} \# 7+$} & \multirow{2}{*}{$\mathrm{C \# m} \mathrm{7+}$} & \multirow{2}{*}{ A $\mathrm{Mm}$} & Am & 1 \\
\hline & & & & & $\mathrm{A}$ & 2 \\
\hline & \multirow{2}{*}{ A6b } & \multirow{2}{*}{ F 7+ } & \multirow{2}{*}{ Fm 7+ } & \multirow{2}{*}{$\mathrm{C} \# \mathrm{Mm}$} & $\mathrm{C \# m}$ & 1 \\
\hline & & & & & $\mathrm{C \#}$ & 2 \\
\hline & \multirow{2}{*}{$\mathrm{C \# 6b}$} & \multirow{2}{*}{ A $7+$} & \multirow{2}{*}{ Am 7+ } & \multirow{2}{*}{ F Mm } & Fm & 1 \\
\hline & & & & & $\mathrm{F}$ & 2 \\
\hline \multirow{6}{*}{ Ciclo 2} & \multirow{2}{*}{ D6b } & \multirow{2}{*}{$\mathrm{Bb} 7+$} & \multirow{2}{*}{ Bbm7+ } & \multirow{2}{*}{$\mathrm{F} \# \mathrm{Mm}$} & $\mathrm{F} \# \mathrm{~m}$ & 4 \\
\hline & & & & & F\# & 5 \\
\hline & \multirow{2}{*}{$\mathrm{F} \# 6 \mathrm{~b}$} & \multirow{2}{*}{ D7+ } & \multirow{2}{*}{ Dm7+ } & \multirow{2}{*}{$\mathrm{Bb} \mathrm{Mm}$} & $\mathrm{Bbm}$ & 4 \\
\hline & & & & & $\mathrm{Bb}$ & 5 \\
\hline & \multirow{2}{*}{$\mathrm{Bb} 6 \mathrm{~b}$} & \multirow{2}{*}{$\mathrm{F} \# 7+$} & \multirow{2}{*}{ F\#m7+ } & \multirow{2}{*}{$\mathrm{D} \mathrm{Mm}$} & Dm & 4 \\
\hline & & & & & $\mathrm{D}$ & 5 \\
\hline \multirow{6}{*}{ Ciclo 3} & \multirow{2}{*}{$\mathrm{B} 6 \mathrm{~b}$} & \multirow{2}{*}{ G7+ } & \multirow{2}{*}{ Gm7+ } & \multirow{2}{*}{$\mathrm{Eb} \mathrm{Mm}$} & Ebm & 7 \\
\hline & & & & & $\mathrm{Eb}$ & 8 \\
\hline & \multirow{2}{*}{ Eb6b } & & & & $\mathrm{Gm}$ & 7 \\
\hline & & B7+ & Bm7+ & $\mathrm{G} \mathrm{Mm}$ & G & 8 \\
\hline & & & & & $\mathrm{Bm}$ & 7 \\
\hline & G6b & Eb7+ & Ebm7+ & B Mm & B & 8 \\
\hline & & & & CM & $\mathrm{Cm}$ & 10 \\
\hline & Ab6b & E7+ & Em7+ & $\mathrm{CMm}$ & C & 11 \\
\hline Cis 1 & $C G \mathrm{~b}$ & 7 & 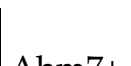 & $\Gamma_{\mathrm{M}}$ & Em & 10 \\
\hline $\operatorname{cic} 10^{4}$ & Con & AD/t & ADIIt T & L IVIIIt & $\mathrm{E}$ & 11 \\
\hline & & & & & $\mathrm{Abm}$ & 10 \\
\hline & EOD & $\mathrm{C}+$ & $\mathrm{cm} /+$ & AD $\mathrm{IVIm}$ & $\mathrm{Ab}$ & 11 \\
\hline
\end{tabular}

Tabela 1: as regiões Euler, dispostas em quatro ciclos, levando às regiões hexatônicas. 
As regiões Euler atuam, portanto como "sinapses semitonais"11 capazes de conectar as zonas de condução de vozes dos ciclos octatônicos (tétrades) aos hexatônicos (tríades). No gráfico resultante (Fig. 16a), as regiões Euler são conectadas às "torres octatônicas" (linhas de cor laranja e verde) e quando atingem o limite da elipse que as envolvem, revelam a conexão entre as zonas de condução de vozes dos ciclos OCTA e HEXA.

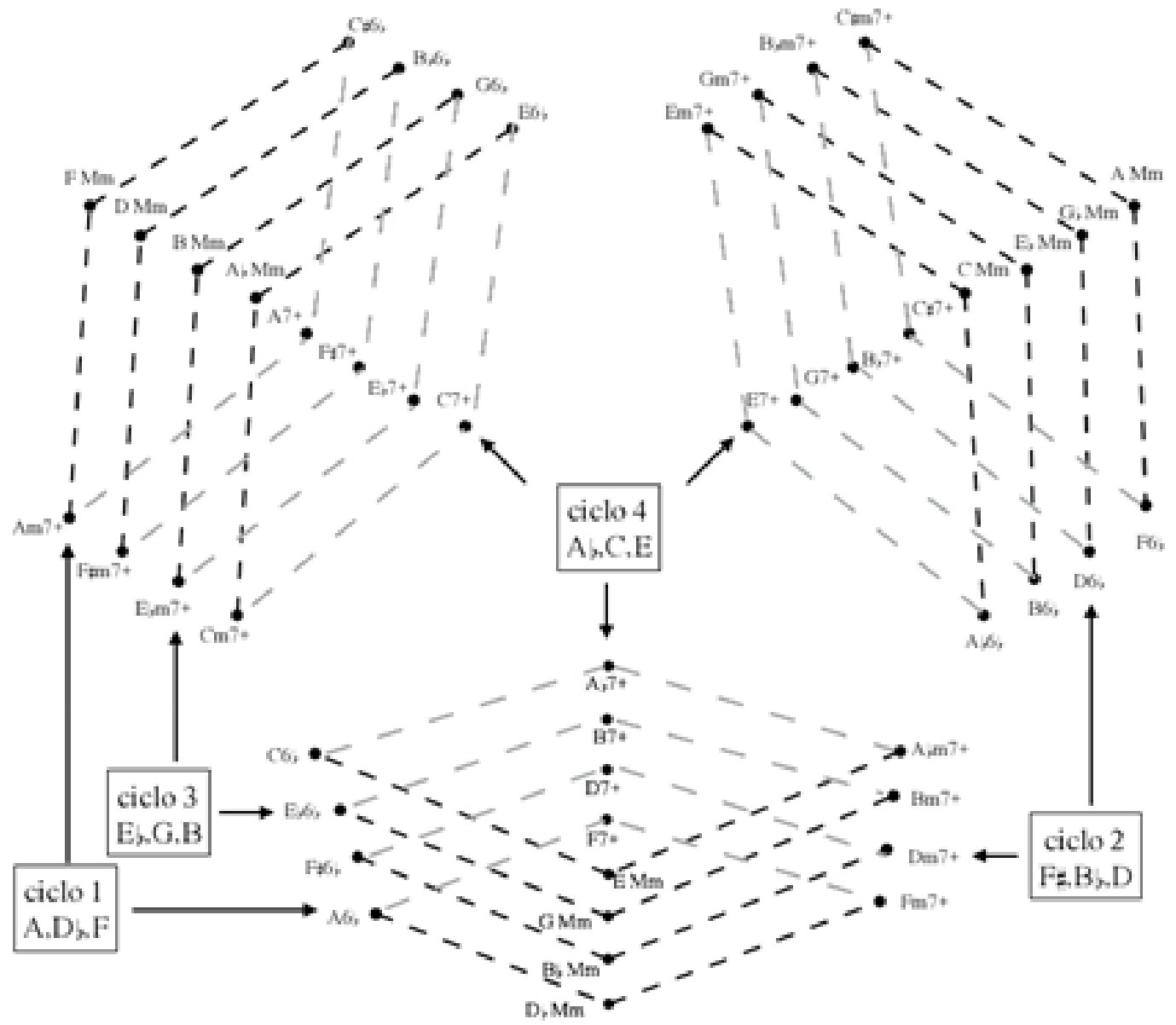

Figura 10: Gráfico das regiões Euler e seus quatro ciclos.

${ }^{11} \mathrm{O}$ termo "sinapse" é empregado aqui pensando em seu sentido literal, que pode ser traduzido do grego como "ação de juntar"; assim, se estabelece uma analogia com as ligações entre acordes e os neurônios. 


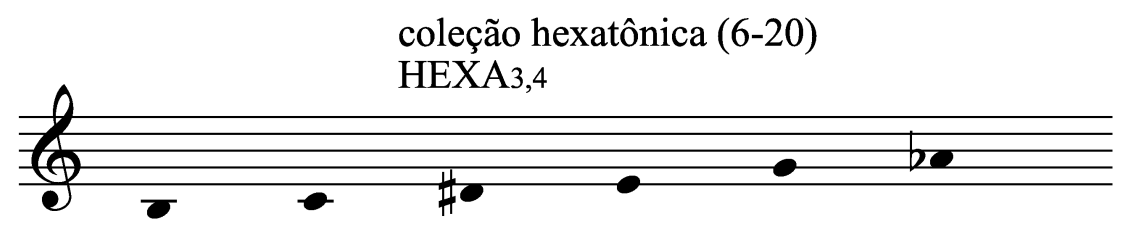

Figura 11: Coleção hexatônica resultante das tétrades presentes na região Euler ilustrada acima (Fig. 9)

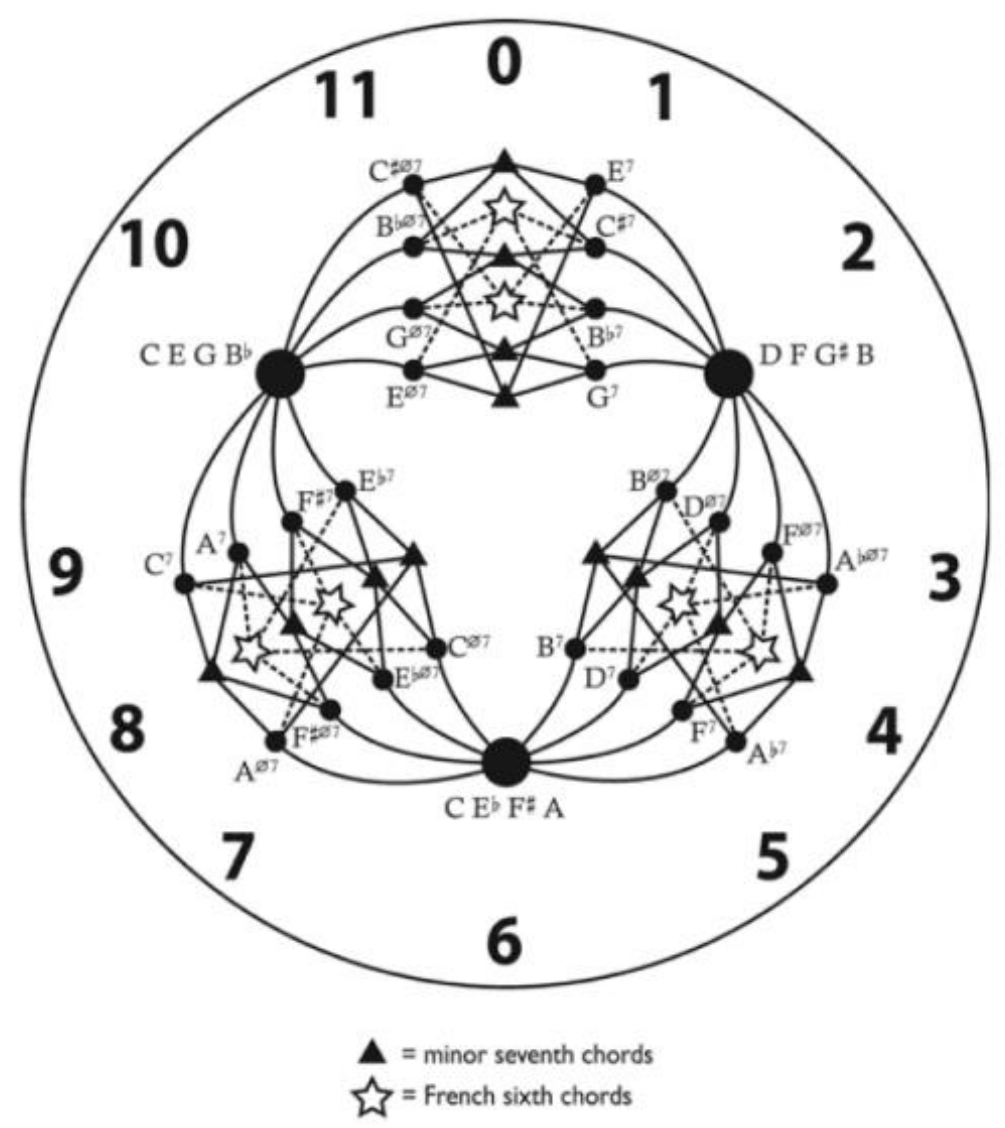

Figura 12: Gráfico “4-cube trio" atribuído a Jack Douthett (Cohn, 2012, p. 158) ${ }^{12}$

${ }^{12} \mathrm{O}$ acorde da zona de condução 10 é Dó\# diminuto.

\section{MUSICA THEORICA}

Revista da Associação Brasileira de Teoria e Análise Musical

Journal of the Brazilian Society for Musical Theory and Analysis

@ TeMA 2016 - ISSN 2525-5541 
(b)

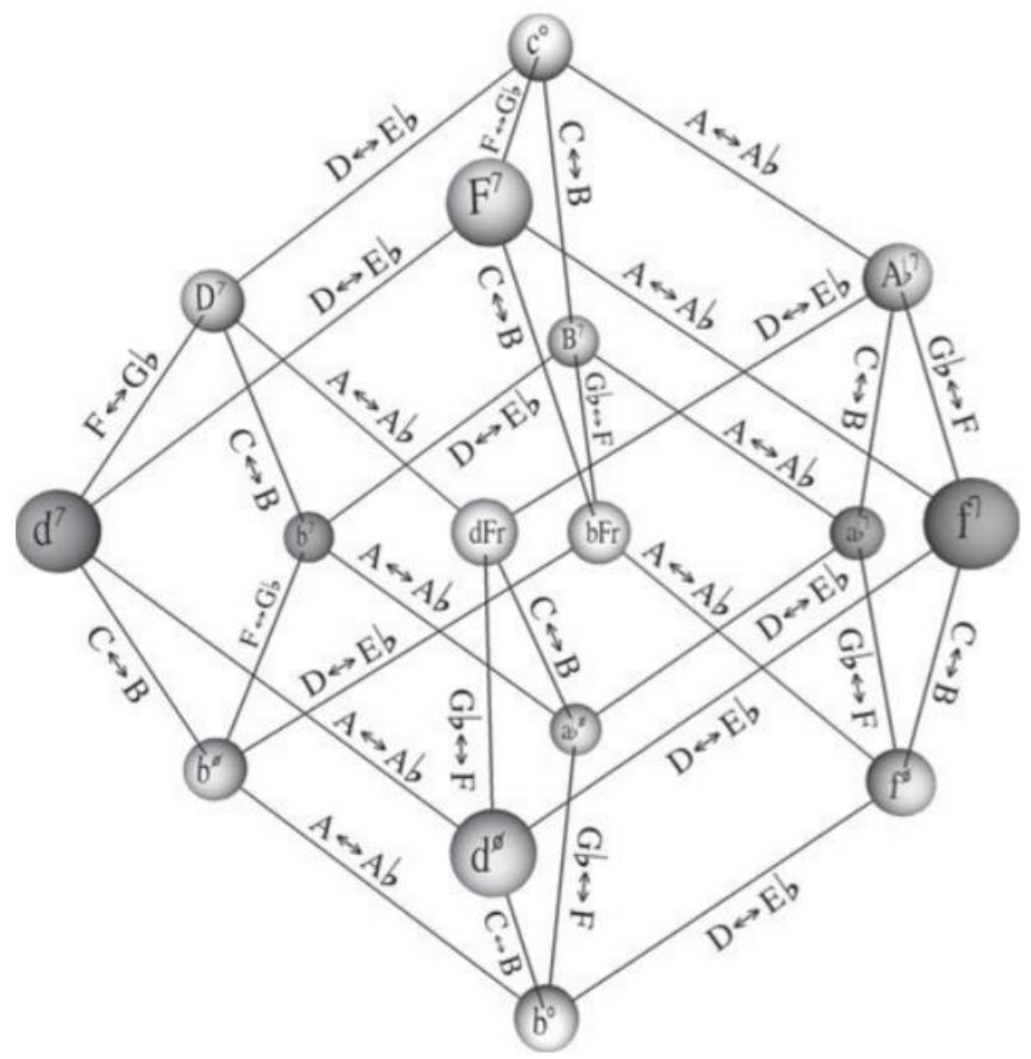

Figura 13: Representação tridimensional da zona de condução de vozes 4 do "4-cube trio" como um conjunto de cubos em quatro dimensões, o tesserato (tesseract)

(Tymoczko, 2011, p. 106)

As zonas de condução de vozes, numeradas de 0 a 11, correspondem à soma das classes de altura de cada acorde inserido em uma zona particular. Seja a zona de condução 3, por exemplo: nela vemos inicialmente a tríade aumentada de Réb (acorde da região Weitzmann que interliga os ciclos hexatônicos), cujas classes da altura são: $1+5+9=15=3$ (mod. 12). Todos os acordes presentes nessa área do gráfico apresentam a mesma soma; Réb aumentado conecta-se por movimento mínimo com os acordes da região Euler: Fá maior com $6^{\underline{a}} \mathrm{~m}$ (ciclo 1 ) e Ré menor com 7ª maior (ciclo 2) (Fig. 14) ${ }^{13}$.

${ }^{13}$ Cabe observar que a tríade aumentada pode ir a outros pontos, dada sua simetria; assim, Réb aumentado pode transformar-se em Sib menor com sétima maior (ciclo 2, zona 1) ou Dó\# com sexta menor (ciclo 1, zona 11); ou mesmo em Lá com sexta menor (ciclo 1, zona 7) ou Fá\# menor com sétima maior (ciclo 2, zona 9). 


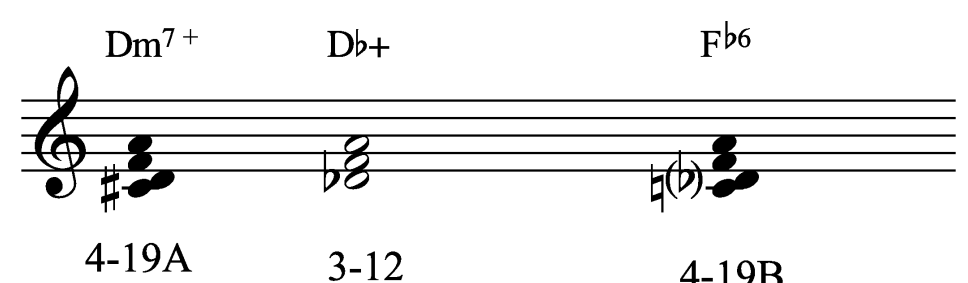

Figura 14: Conexão entre a tríade aumentada e os acordes da classe 4-19, na zona de condução de vozes 3

As tríades menores da zona de condução 4, e as tríades maiores da zona de condução 5 (Fá\#, Ré e Sib) conectam-se com o ciclo 2 das regiões Euler, tétrades da classe 4-17 (maior-menor) que compartilham as mesmas fundamentais. Assim, Fá\# maior e fá\# menor transformam-se em Fá\# maior-menor por deslocamento de semitom associado com a função SPLIT (Fig. 15).

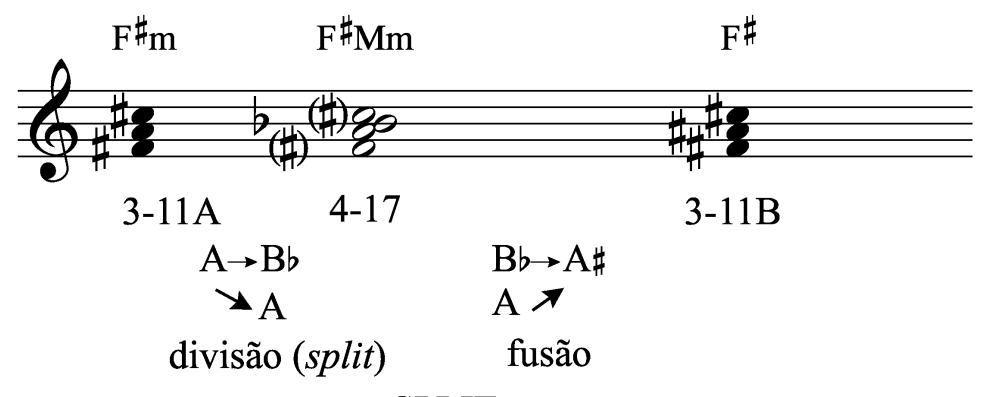

SPLIT

Figura 15: Conexão entre as classes 3-11 e 4-17, do ciclo HEXA (zonas 4 e 5) e da região Euler (ciclo 2) respectivamente

O gráfico resultante, denominado "planetário tonal"14 (Fig. 16a) apresenta as sinapses semitonais entre os ciclos comentados acima; a elipse que envolve todo o sistema representa a região dos ciclos hexatônicos na "dança dos cubos". Nota-se que as tétrades concentradas nas zonas de condução de numeração par são acordes que possuem eixo de simetria ${ }^{15}$ (CCA 4-26, 4-25, 4-20 e 4-17); as zonas de condução ímpares concentram tétrades "assimétricas". Há, portanto, uma assimetria entre os ciclos OCTA e HEXA, pois no ciclo hexatônico os eixos

\footnotetext{
${ }^{14}$ A expressão "planetário" aqui empregada remete diretamente ao uso do termo para se referir ao "anfiteatro em cúpula, dotado de mecanismo mediante o qual se transmite à assistência a situação e o movimento do sistema solar" (Dicionário Aurélio, 2 ${ }^{\mathrm{a}}$ ed. Rio de Janeiro: Nova Fronteira, p. 1343); portanto, é feita analogia entre o sistema solar e o sistema tonal como espaços de coordenadas e o mapeamento das distâncias entre os objetos inseridos nesses sistemas.

${ }^{15}$ Os CCA 4-26, 4-25, 4-20 e 4-17 têm eixo de simetria por inversão - ou "eixo inversivo", segundo a tradução de Ricardo Bordini (Straus, 2013, pp. 145-152) - que é um dos fatores importantes para o estabelecimento de centricidade na música pós-tonal da primeira metade do século XX.
} 
simétricos são dispostos no centro das regiões Weitzmann, isto é, nas tríades aumentadas nas zonas de condução 0, 3, 6 e 9. Essa assimetria se manifesta claramente pelo posicionamento, por exemplo, dos acordes de sexta francesa (zonas 0, 4 e 8) em relação às tríades aumentadas.

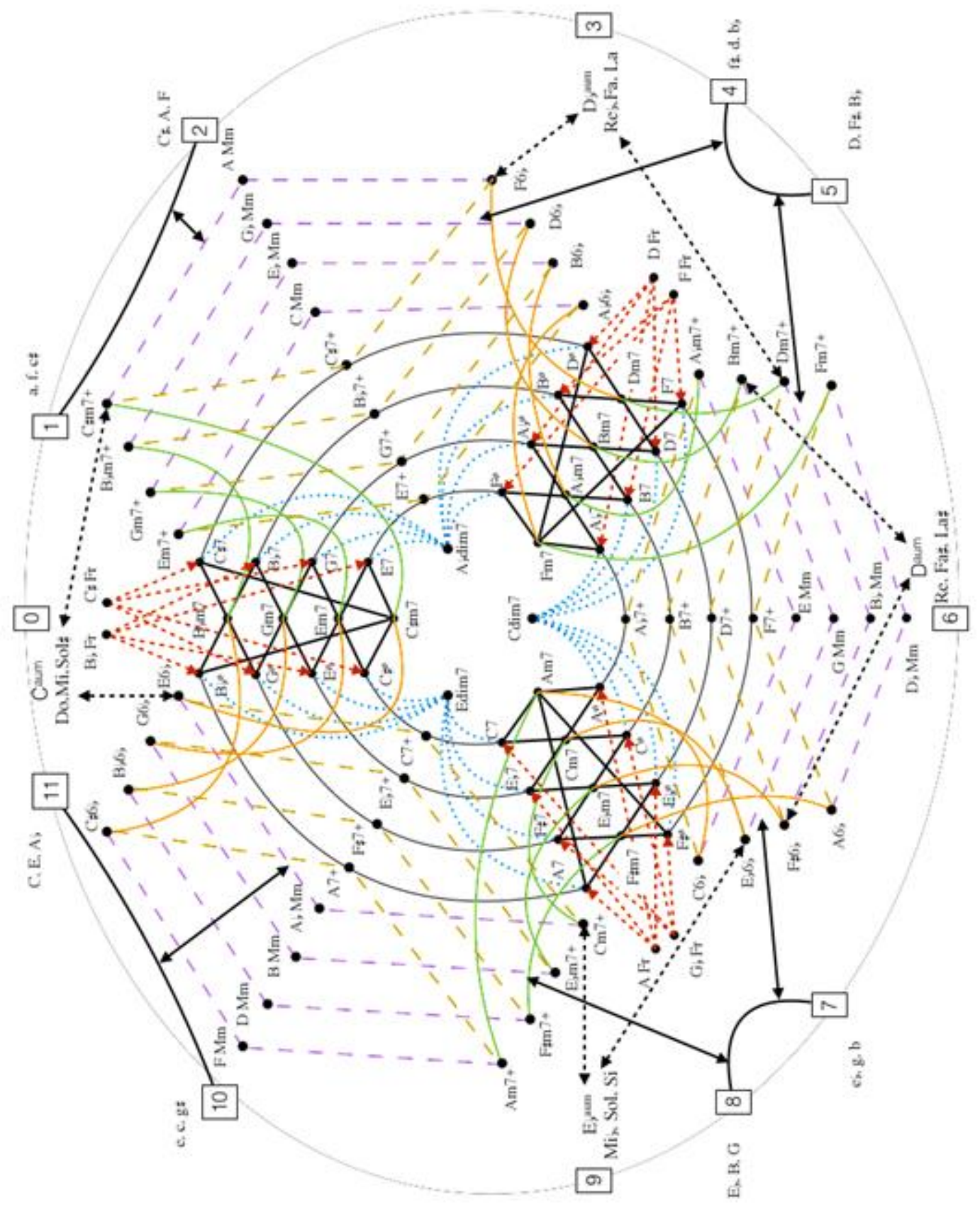

Figura 16a: Gráfico "planetário tonal". As sinapses semitonais entre os ciclos octatônicos e hexatônicos, proporcionadas pelas regiões Euler. Seguindo a notação de Cohn (2012), as tríades maiores são indicadas por letras maiúsculas, as tríades menores por minúsculas (posicionadas do lado externo da elipse) e as tríades aumentadas com a cifra "aum"; as demais cifras mantém o padrão adotado ao longo deste texto. 
O gráfico com as classes de altura posicionados em elipses concêntricas, uma espécie de "radar", mostra os três eixos com CCA simétricos que se entrecruzam no centro desse campo harmônico, indo de 4-17 a 4-25 (Fig. 16b). Evidentemente, a denominação por CCA oblitera as relações mais específicas de condução de vozes observadas nos acordes, mas o gráfico é útil por mostrar a função quase "gravitacional" dos agrupamentos simétricos nessas regiões delineadas a partir de tríades e acordes com sétima.

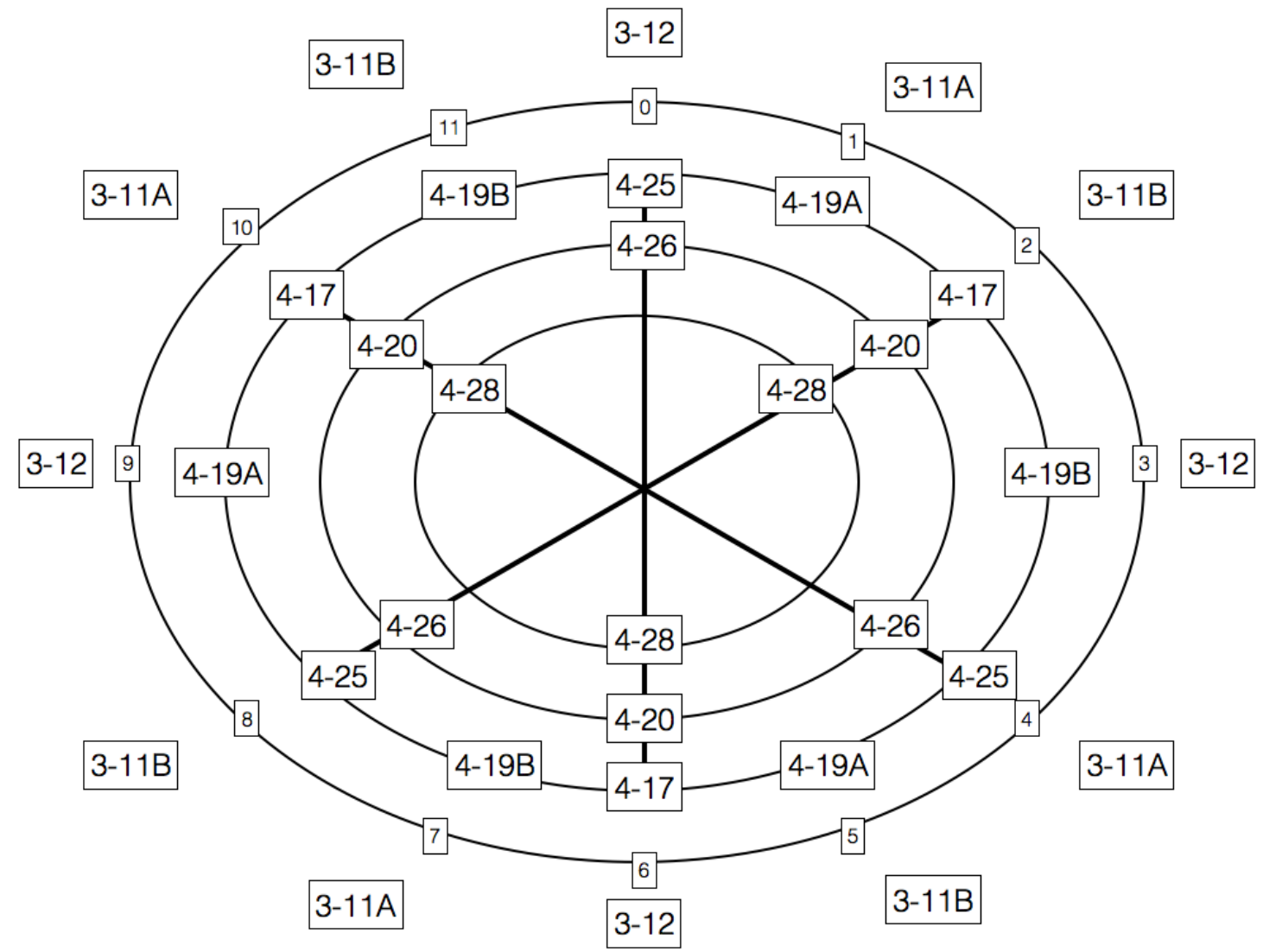

Figura 16b: Situação dos CCA no "radar", mostrando sinapses semitonais entre os ciclos octatônicos e hexatônicos. Destaque para os três eixos com CCA simétricos.

\section{4 - Uma Breve Análise de Villa-Lobos}

A dicotomia entre acordes com e sem eixo de simetria, ou seja, acordes "simétricos" e "assimétricos", é de suma importância para a compreensão dos procedimentos harmônicos empregados por Villa-Lobos. Foi uma passagem do primeiro movimento do Quarteto de Cordas $n^{-} 2$ (1915) que chamou a atenção para o papel do CCA 4-19 e sua contraposição a 3-12, 4-20 e 4-26 (Fig. 17). Apesar de se tratar de uma obra de juventude, essa passagem (c. 36-45) revela como simetria 
e assimetria são funcionalmente análogas à oposição consonância/dissonância no estilo do compositor. A condução de vozes na camada de acompanhamento (a cargo de viola e cello) é predominantemente por deslocamento de um semitom entre cada par de acordes, com duas exceções pontuais: a) a transformação de 422 em 4-26 (c. 37); b) a transformação de 4-26 em 4-25 (sexta francesa, c. 40). A primeira transformação tem pelo menos duas soluções pelo caminho mais curto (Fig. 18), uma delas, no gráfico sem as regiões Euler, requer cinco movimentos de semitom; a região Euler reduz a distância entre os pontos para quatro movimentos de semitom, pois possibilita a transformação em uma tríade de Sol menor (zona de condução 7), que atua como uma espécie de atalho, conectandose por movimento de semitom com o ciclo 3, zona 1 (Sol menor com sétima menor).

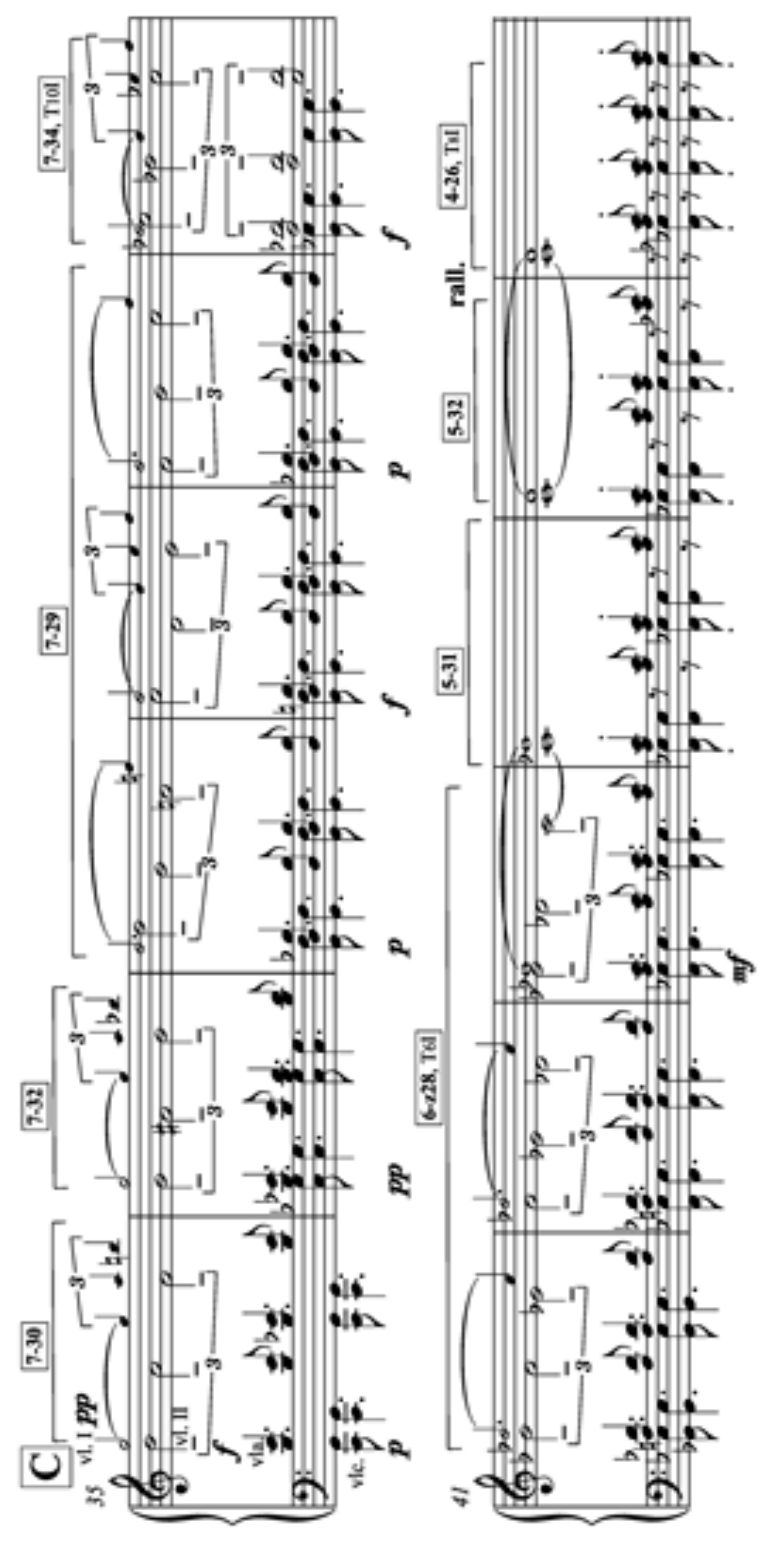

Figura 17: Villa-Lobos, QC2, I, c. 35-46 
A passagem revela nitidamente a importância dos acordes simétricos, assinalados pelos retângulos (Fig. 18). Essa tendência se acentua em obras posteriores a 1918, quando o compositor sedimenta sua própria linguagem harmônica ${ }^{16}$.

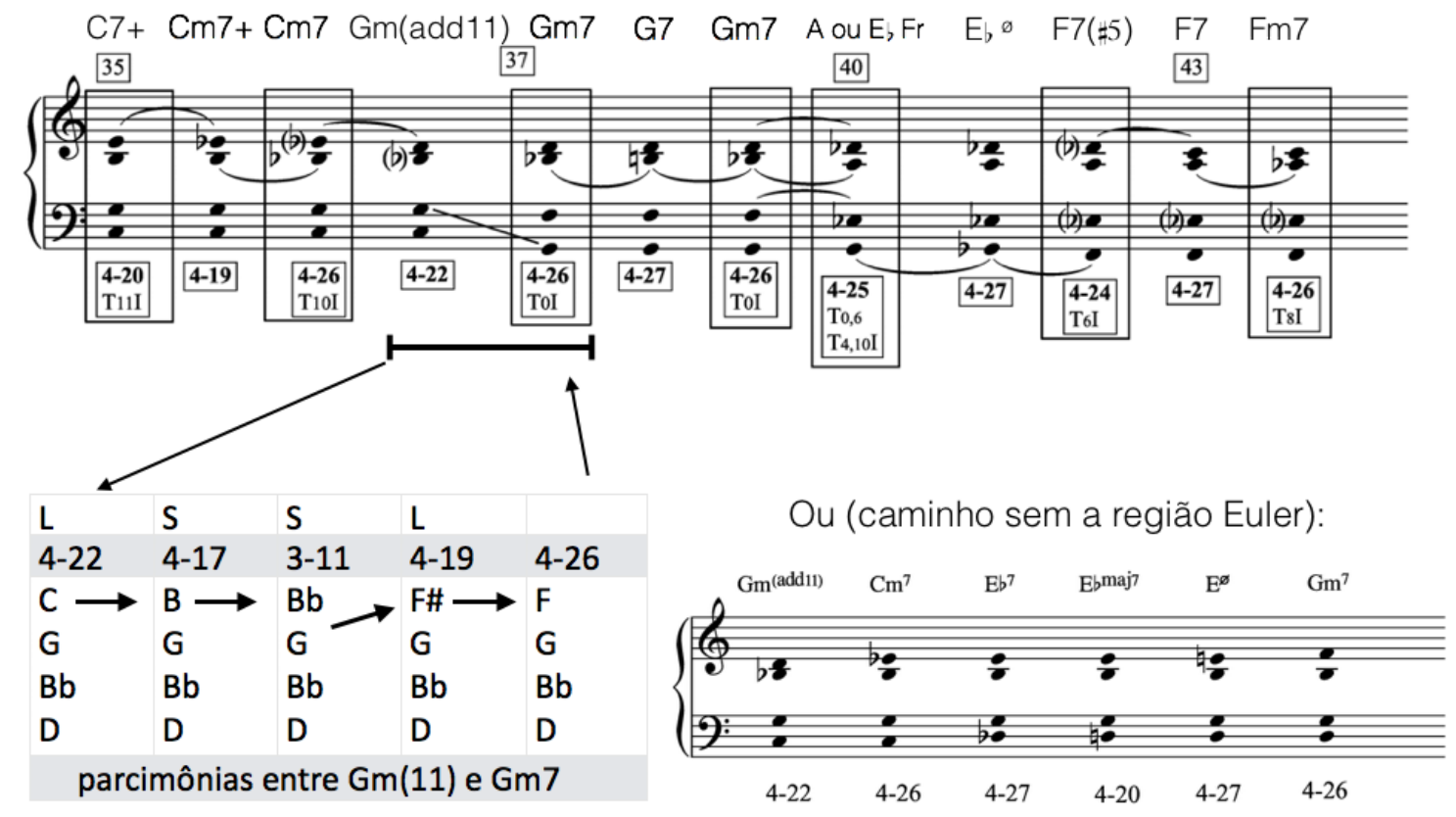

Figura 18: Villa-Lobos, QC2, I, c. 35-46, redução e análise dos acordes de acompanhamento (viola e cello)

\footnotetext{
${ }^{16}$ Cheguei a essa conclusão após analisar todo o ciclo de quartetos de cordas de Villa-Lobos, onde se pode observar sua preferência por realizar cadências sobre acordes com eixo de simetria. Esse estudo será publicado em breve no formato de livro.
} 


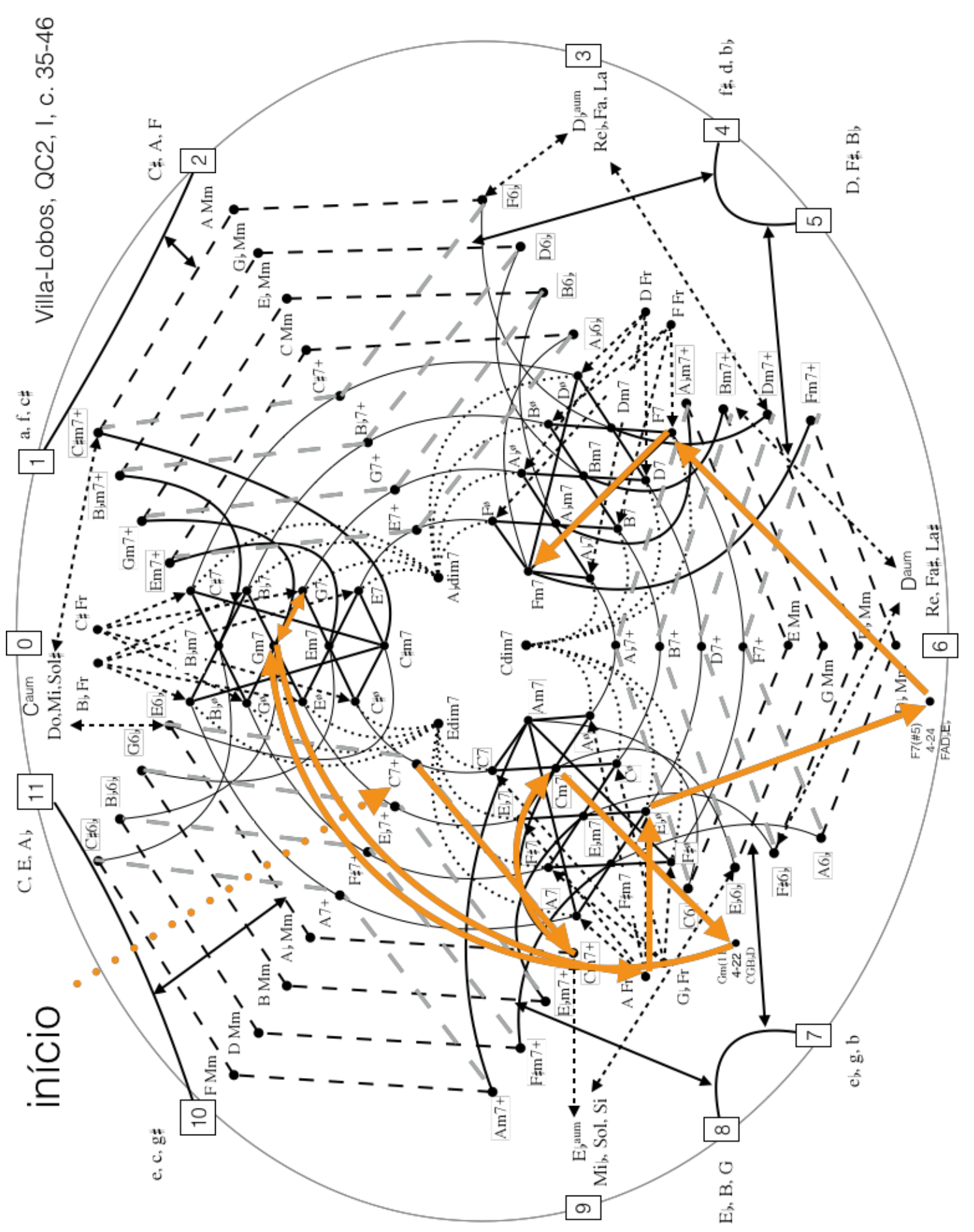

Figura 19: Villa-Lobos, QC2, I, c. 35-46, análise das transformações no "planetário tonal" 


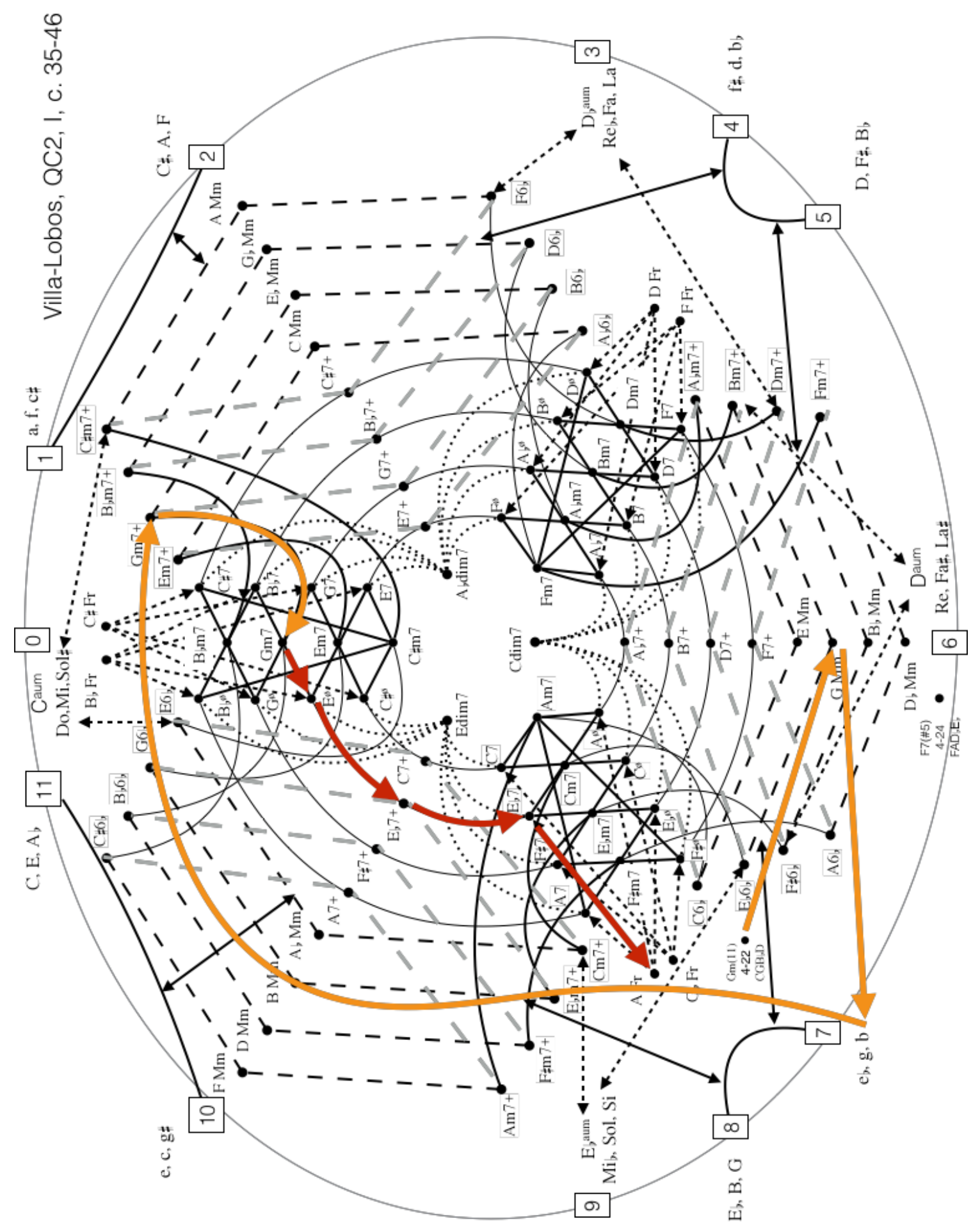

Figura 20: caminhos parcimoniosos entre 4-22 e 4-26 (laranja) e 4-26 e 4-25 (vermelho) 
A Figura 19 apresenta as transformações tal como ocorrem no trecho estudado. Foi necessário definir como "auxiliares" dois acordes (4-22 e 4-24), não encontrados em nenhum dos ciclos aqui demonstrados, posicionados no gráfico segundo a soma de suas classes de altura, respectivamente nas zonas de condução 7 e $6{ }^{17}$.

A Figura 20 mostra os caminhos mais curtos possíveis entre as passagens não parcimoniosas, justamente os passos de 4-22 para 4-26 (na cor laranja) e de 4-26 para 4-25 (em vermelho). O acorde de Sol menor com 11'a acrescentada, SolSib-Ré-Dó (4-22) transforma-se sucessivamente em Sol maior-menor (4-17) e retorna à zona de condução 7 para a tríade de Sol menor (3-11A), que está conectada com o ciclo 3 da região Euler, onde está o acorde de Sol menor com sétima maior (4-19A); o passo derradeiro é o deslizamento que leva para Sol menor com sétima (4-26). A transformação de Sol menor com sétima no acorde de sexta francesa é realizada com quatro passagens de semitom, conectando as zonas de condução 0 e 8 .

\section{5 - Considerações Finais}

A teoria neo-riemanniana e seus desdobramentos oferecem propostas eficazes para uma avaliação de processos dinâmicos do movimento harmônico, mapeando os movimentos de condução de vozes e quantificando a distância tonal sem a concepção tradicional a partir da fundamental dos acordes.

Os gráficos realizados por Cohn, Douthett/Steinbach, Tymoczko e Baker proporcionam entendimento para a aferição da distância tonal em passagens triádicas ou com acordes de sétima, na área das chamadas mediantes cromáticas; todavia, é difícil encontrar passagens exclusivamente fundadas em tríades ou tétrades. As regiões Euler mapeiam algumas áreas "esquecidas" entre esses campos tonais, as quais sugerem - por meio de acordes auxiliares - a possibilidade de mapear entidades harmônicas pós-tonais encontradas com certa frequência na música da primeira metade do século XX.

Os acordes aqui chamados "auxiliares", são potencialmente integrantes de outras regiões, revelando um "universo em constante expansão" no tocante às interligações por semitom que ainda restam para serem mapeadas ${ }^{18}$. O CCA 4-22

\footnotetext{
${ }^{17}$ Conforme observado acima, esses acordes também manifestam a mesma propriedade simétrica ou assimétrica em relação à zona de condução de vozes a qual pertencem. Enquanto a CCA 4-22 é assimétrico (zona ímpar), 4-24 apresenta eixo de simetria por inversão (zona par). O CCA 4-24 pode vir a integrar as regiões Euler, pois conecta parcimoniosamente os ciclos entre si, o que será demonstrado em outra ocasião.

${ }^{18}$ Robert Morris demonstra como se pode construir "espaços de condução de vozes de qualquer grau de complexidade e seletividade [closure]" (Morris, 1998, p. 203).
} 
na conformação apresentada na passagem analisada no Quarteto de cordas $n^{\underline{o}} 2$ de Villa-Lobos, $\mathrm{Gm}(11)$, pode mapear-se com sua inversão, $\mathrm{Bb}(9)$, resultando nas versões 4-22A e 4-22B respectivamente; do mesmo modo, o acorde F7(\#5) (FN 4$\left.24, \mathrm{~T}_{6} \mathrm{I}\right)$, cujas suas inversões B7(\#5), Ab7(\#5) e D7(\#5), também são situadas na zona de condução de vozes 6; por outro ponto de vista, o acorde F7(\#5) deriva de Réb aumentado do mesmo modo que Db7(\#5) e A7(\#5) (Fig. 21) ${ }^{19}$.

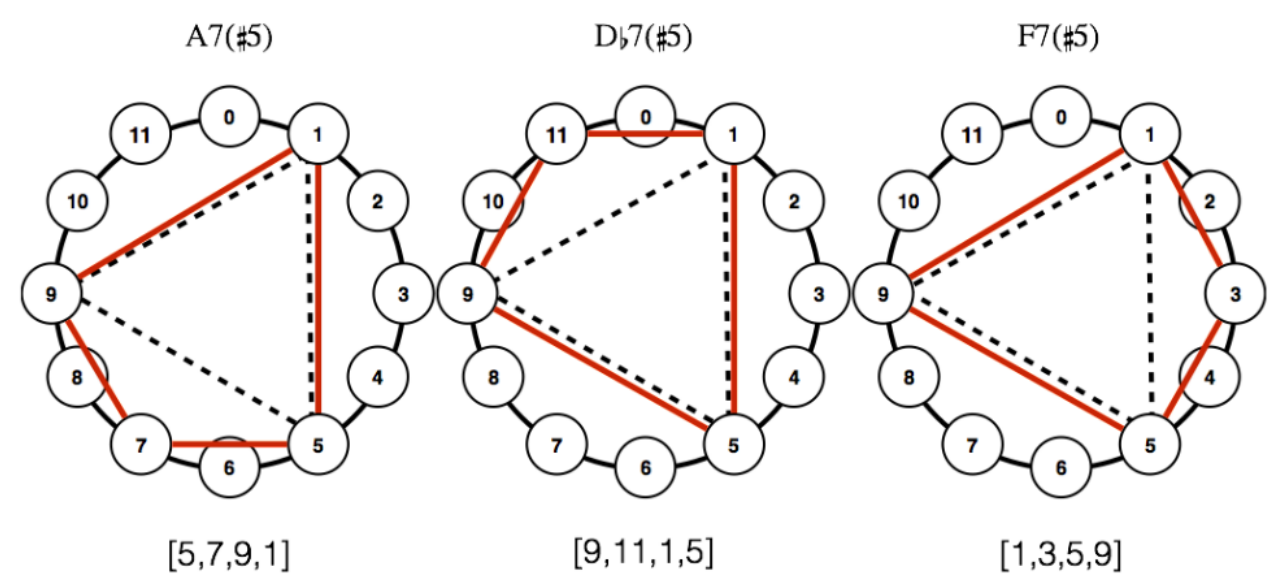

Figura 21: três das doze versões de 4-24, e sua transformação por acréscimo de tom inteiro a partir da tríade aumentada $[1,5,9]$

O gráfico "planetário tonal" aqui apresentado pode contribuir para a compreensão das transformações harmônicas contextuais ouvidas na música de Villa-Lobos, e servir como ferramenta para análise de compositores do final do século XIX e início do XX, ampliando nosso entendimento do conceito de distância tonal. A pesquisa com as outras conexões a partir de combinações ainda não estudadas pode revelar não só áreas ainda não mapeadas nas regiões estudadas como também incorporar acordes não triádicos.

\footnotetext{
${ }^{19}$ Há 12 versões possíveis do CCA 4-24, o qual também é derivado da tríade aumentada (como o 4-19), por meio do acréscimo de tom inteiro. Essas versões se agrupam em três grupos de quatro acordes, alinhados com as tétrades diminutas nas zonas de condução de vozes 2, 6 e 10.
} 


\section{Referências}

1. Albuquerque, Joel e Salles, Paulo de Tarso. 2014. Teoria dos Conjuntos versus Teoria neo-Riemanniana: duas abordagens interdependentes na análise dos Choros No 4 e Choros No 7 de Villa-Lobos. In: Anais do VI Encontro de Musicologia de Ribeirão Preto. Ribeirão Preto: USP.

2. Baker, Steven. 2003. "Neo-Riemannian Transformations and Prolongational Structures in Wagner's Parsifal". PhD Dissertation, Florida State University.

3. Callender, Clifton. 1998. Voice Leading Parsimony in the Music of Alexander Scriabin. Journal of Music Theory, v. 42, n. 2, p. 219-233.

4. Childs, Adrian. 1998. Moving beyond Neo-Riemannian Triads: Exploring a Transformational Model for Seventh Chords. Journal of Music Theory, v. 42, n. 2, p. 181-193.

5. Cohn, Richard. 1996. Maximally Smooth Cycles, Hexatonic Systems, and the Analysis of Late-Romantic Triadic Progressions. Music Analysis, v. 15, n.1, p. 940 .

6. 2012. Audacious Euphony: Chromaticism and the Triad's Second Nature. Oxford and London: Oxford University Press.

7. Douthett, Jack e Steinbach, Peter. 1998. Parsimonious Graphs: A Study in Parsimony, Contextual Transformations, and Modes of Limited Transposition. Journal of Music Theory, v. 42, n. 2, p. 241-263.

8. Fernandez, Oscar Lorenzo. 1946 (abril). A contribuição harmônica de VillaLobos para a música brasileira. Boletim Latino Americano de Música, tomo VI, $1^{\text {a }}$ parte. Montevidéu: Instituto Interamericano de Musicologia, p. 283-300.

9. Gollin, Edward. 1998. Some Aspects of Three-Dimensional “Tonnetze”. Journal of Music Theory, v. 42, n. 2, p. 195-206.

10. . 2009. Combinatorial and Transformational Aspects of Euler's "Speculum Musicum". Mathematics and Computation in Music, v. 37, p. 406-11.

11. 2011. From Matrix to Map: "Tonbestimmung", the "Tonnetz", and Riemann's Combinatorial Conception of Interval. In: Gollin, E. e Rehding, A. The Oxford Handbook of Neo-Riemannian Theories. Oxford: Oxford University Press. 
12. Lewin, David. 1982. A Formal Theory of Generalized Tonal Functions. Journal of Music Theory, v. 26, n. 1, p. 23-60.

13. Menezes, Flo. 2016. Berio e a palavra. In: Menezes, F. (org.). Luciano Berio: legado e atualidade. São Paulo: Editora da Unesp, p. 67-92.

14. Morris, Robert. 1998. Voice-leading Spaces. Music Theory Spectrum, v.20, n.2, p. 175-208.

15. Salles, Paulo de Tarso. 2009. Villa-Lobos: processos composicionais. Campinas: Editora da Unicamp.

16. 2016. Redes de transformação harmônica na obra de Villa-Lobos: uma abordagem derivada da teoria neo-riemanniana. Anais do IV Simpom - Simpósio de Pós-Graduandos em Música. Conferência proferida em 12 de maio de 2016. Rio de Janeiro: Unirio.

17. Straus, Joseph. 2013. Introdução à teoria pós-tonal. São Paulo e Salvador: Editora Unesp/Editora UFBA.

18. Tymoczko, Dmitri. 2011. A Geometry of Music: Harmony and Counterpoint in the Extended Common Practice. Oxford: Oxford University Press.

19. Visconti, Ciro. 2016. Simetria nos Estudos para violão de Villa-Lobos. Jundiaí: Paco Editorial. 